\title{
L L OCASO DE UN GREMIO: SAN ELOY DE SANTIAGO DE COMPOSTELA EN EL SIGLO XIX
}

\author{
ANA PÉREZ VARELA \\ Universidade de Santiago de Compostela \\ ana.perez.varela@hotmail.com
}

\begin{abstract}
Resumen: El presente artículo tiene como objetivo la reconstrucción de la historia del gremio de San Eloy de Santiago de Compostela en el siglo XIX, tema sobre el que todavía no existe ningún estudio. La metodología de nuestra investigación se ha centrado en primer lugar en analizar la bibliografía publicada sobre la desintegración del sistema gremial en España, motivada por el paradigma filosófico de la Ilustración y la liberalización del trabajo. Para aplicarlo al caso de Compostela y en concreto a los plateros, el segundo paso fue el vaciado de los libros consistoriales y las matrículas industriales del Archivo Histórico Universitario de Santiago, fuentes complementadas por los Anuarios de Comercio de la Biblioteca Nacional de Madrid. Todo ello nos ha permitido conocer el estado de las relaciones entre el moribundo gremio y el Concejo durante el ochocientos, establecer las marcas y marcadores de la ciudad, ubicar la zona de obradores de plateros dentro de la urbe y rescatar del olvido una interesante nómina de artesanos que se resistieron a aceptar la pérdida de sus privilegios protegiendo su legado artesanal.
\end{abstract}

Palabras clave: gremios / Santiago de Compostela / siglo XIX / archivo.

\section{THE TWILIGHT OF A GUILD: SAN ELOY OF SANTIAGO DE COMPOSTELA IN THE NINETEENTH CENTURY}

\begin{abstract}
The present paper has as objective the reconstruction of the history of the guild of Saint Eloy of Santiago de Compostela in the nineteenth century, an issue that has not been studied yet. In the first place, our researching methodology was focused on the analysis of the published bibliography about the disintegration of the guild system in Spain, motivated by the philosophic paradigm of the Enlightenment and work liberalisation. In order to apply this reality to the case of Compostela, and in particular, of the silversmiths, the second step was the work in the University of Santiago Historical Archive, where we consulted the Council books and the industrial register, sources completed by the economic yearbooks in the National Library of Madrid. This research has enabled us to reconstruct the state of the relationship between the dying guild and the city Council during the nineteenth century; stablish the marks and markers of the city; locate the area of the silversmithing workshops in the city; and rescue an interesting group of artists from oblivion, who resisted the idea of losing their privileges and artisanal legacy.
\end{abstract}

Key words: guilds / Santiago de Compostela / nineteenth century / archives.

\section{La desintegración del sistema gremial}

La estructura corporativa gremial europea, que hundía sus cimientos en la Edad Media, estaba tan arraigada y asumida que su caída no fue inmediata ni fue aceptada con beneplácito por el sistema tradicional. El germen de su derrumbamiento lo sembró el cambio de paradigma que vino impulsado por el pensamiento ilustrado y las políticas de corte reformista. ${ }^{1}$ El contexto de la llustración había mo-

\footnotetext{
* Fecha de recepción: 15 de abril de 2020 / Fecha de aceptación: 23 de septiembre de 2020.

1 En palabras de Escolano Benito, que creemos, resumen el punto de arranque del que hemos de partir: “[...] la filosofía de la Ilustración revalorizó y difundió las ciencias y las artes útiles, y creó las condiciones para que cristalizara la escuela técnica moderna, como institución pedagógica de apoyo a las nuevas necesidades derivadas de la expansión económica en los comienzos del industrialismo". ESCOLANO BENITO, Agustín, 1982, p. 174.
} 
tivado que la arquitectura mostrase una mayor modernización en el plano de transmisión del conocimiento, en parte porque el pensamiento ilustrado la revistió de una categoría filosófica que la elevó por encima del resto de las artes, y en especial de aquéllas manuales de raíz gremial. La creación de la Academia de San Fernando en 1752 en Madrid y la supresión en sus estatutos de 1755 de las congregaciones o cofradías "para reglar los estudios y práctica de las tres nobles artes", significó el inicio de la irremediable desintegración del sistema gremial tradicional en España, que se haría efectiva en la primera mitad del siglo XIX. Las palabras de Belda Navarro y de la Peña Velasco sintetizan el cambio de paradigma:

"Con la creación de la Real Academia de Bellas Artes de San Fernando y la instauración de un nuevo sistema de enseñanza de las artes en el marco del reformismo ilustrado, se iniciaría el enfrentamiento de dos mundos. La tiranía de los gremios fue sustituida por el nuevo modelo de tiranía que encarnaba la Academia, ahora bien, las determinaciones adoptadas por esta última institución siempre se suponían justificadas, dado que se alegaba que se hacían para lograr la mejora y modernización del país y la utilidad y progreso de las artes y la industria".2

Los célebres Discursos (1774 y 1775) de Pedro Rodríguez de Campomanes (1723-1802) ${ }^{3}$ y el Informe (1785) de Gaspar Melchor de Jovellanos (17441811) ${ }^{4}$ tuvieron una difusión extraordinaria en toda España, especialmente gracias a los Ayuntamientos. Los textos del primero, que Demerson y Demerson calificaron como "el Código y la Biblia de [las Reales Sociedades Económicas de] Amigos del País", 5 insistieron en que los gremios debían de ser estructuras abiertas a todos los artífices competentes, además de dejar claro que la base del conocimiento del artista pasaba por una sólida formación científica y teórica. ${ }^{6}$ No pretendió eliminar a los gremios, sino mantenerlos dentro del sistema productivo quitándoles su independencia y los aspectos más retrógrados heredados del es- quema de transmisión del conocimiento medieval, tan obsoleto en el Siglo de las Luces. De este modo, criticó los privilegios endogámicos, la corrupción de los exámenes, la excesiva reglamentación, o la prohibición del trabajo de la mujer, abogando por exámenes públicos, legitimados y controlados por el Ayuntamiento. Por su parte, el texto de Jovellanos es todavía más crítico, donde el ilustrado apuntó la necesidad de la apertura de los oficios a todo aquél que quisiese ejercerlos libremente, insistiendo en la necesidad del trabajo femenino, y cargando violentamente contra las condiciones exclusivistas y cerradas de los gremios. ${ }^{7}$

Gracias al empeño de ilustrados como los dos susodichos, o el conde de Floridablanca (1728-1808), ${ }^{8}$ se consiguió en 1875 que el gobierno de Carlos III declarase el libre ejercicio de las bellas artes, reconociendo de forma explícita que su conocimiento y práctica era necesarios para que avanzasen las artes industriales. ${ }^{9}$

En 1778 Antonio Martínez (1750-1978) fundó en Madrid, bajo patrocinio real, la Escuela y la Real Fábrica de Platería, que vino a significar la llegada a España de las técnicas ilustradas de aprendizaje aplicadas al arte de la plata. Hasta su extinción en 1864, la institución fue lo más destacado e innovador de la platería española. ${ }^{10}$ Además, significó un reflejo de la inminente desintegración del sistema gremial, al ser Martínez autorizado por la monarquía para examinar de maestro a los plateros sin rendir cuentas al gremio de San Eloy. ${ }^{11}$ La Fábrica supuso una auténtica revolución dentro del ámbito nacional, marcando la moda de la platería del país durante al menos setenta años, y estimulando el consumo de plata civil. Implantó nuevas técnicas, definió la especialización de labores, el refinamiento de la producción, e importó modelos de Inglaterra y Francia, dentro del nuevo concepto de industria de carácter artístico. Además, los propios discípulos de la escuela fueron abriendo a su vez obra-

\footnotetext{
2 BeLdA NAVARRO, Cristóbal; PEÑA VELASCO, María de la Concepción, 1992, p. 17.

3 Sobre su figura y obra, véase CAMPOMANES, Pedro Rodríguez de; REEDER, John (ed.), 1975, p. 14-37.

${ }^{4}$ Sobre su figura y obra, véase POLT, John, 1971.

5 DEMERSON, Jorge; DEMERSON, Paula de, 1977, p. 178.

${ }^{6}$ BELDA NAVARRO, Cristóbal; PEÑA VELASCO, María de la Concepción, 1992, p. 19-22.

7 GARCÍA CANTÚS, María Dolores, 1985, p. 27.

8 Sobre su figura y obra, véase HERNÁNDEZ FRANCO, Juan, 2008.

9 DÍEZ BENITO, Juan José, 2002, p. 193-194.

10 Sobre la Real Fábrica de Martínez podríamos citar un sinfín de trabajos. Por razones de espacio nos remitimos al volumen monográfico: MARTíN, Fernando (com.), 2011, con estudios de varios historiadores.

11 FERNÁNDEZ, Alejandro; MUNOA, Rafael; RABASCO, Jorge, 1984, p. 62.
} 
dores que continuaron ese espíritu modernizador, que en palabras de Alonso Benito, "se realimentaba de forma continua desde la corte con el lanzamiento de nuevas tendencias y modelos". ${ }^{12}$

El decreto promulgado por las Cortes de Cádiz en 1813 hizo efectiva la desintegración del sistema y significó la posibilidad de ejercer el libre comercio, permitiendo a cualquier persona realizar un oficio sin estar examinado. Sin embargo, la norma fue derogada y establecida en varias ocasiones durante el reinado de Fernando VII. El decreto del 9 de marzo de 1842 reiteró la disposición de 1813, ordenando la conversión de los colegios de plateros en asociaciones artísticas y eliminando los exámenes para obtener el título de maestro. Es el momento que se señala de forma generalizada en España como la efectiva desintegración del sistema gremial. ${ }^{13}$

\section{El reflejo del contexto reformista en Santiago de Compostela}

En paralelo al contexto reformista nacional, Barriocanal López señaló que la desaparición de las estructuras gremiales fue promovida por economistas ilustrados gallegos del último cuarto del siglo XVIII como Antonio Sánchez Vaamonde (17491806),$^{14}$ quien acusó a las exageradas contribuciones del gremio del empobrecimiento y atraso de los artesanos, que estaban continuamente pleiteando. ${ }^{15}$ Sin embargo, los síntomas de la desintegración de los gremios en Santiago pueden verse reflejados de manera más clara si hacemos un seguimiento de los documentos consistoriales.

Desde los cimientos históricos del sistema gremial, y como fue habitual en cualquier territorio, el Concejo de Santiago adoptó medidas de control de calidad para certificar el buen uso de la materia prima como la plata, y evitar los engaños y fraudes en las transacciones de compraventa. Entre estas estrategias, las directrices más destacadas fueron el establecimiento de visitas periódicas a los obradores; la designación de marcadores que certificasen la calidad del material; ${ }^{16}$ y las medidas proteccionistas contra piezas y artistas foráneos. ${ }^{17}$ Además, y como también fue habitual en cualquier ciudad, el propio gremio reguló este tipo de medidas de forma interna a través de sus ordenanzas, que establecían las reglas de la corporación.

Existen cuatro documentos de finales del siglo XVIII y principios del siglo XIX que vienen a contribuir a explicar este contexto reformista. El primero, de 1770, es el informe del Concejo compostelano, pedido por el Intendente bajo orden de Pedro Abarca de Bolea, conde de Aranda. Este, dentro de esta órbita de reformas centralistas, había reclamado una lista de todas las cofradías, congregaciones y gremios de España para suprimir aquellas que no ofrecían una verdadera razón de ser y controlar las restantes. En este documento se detallan una lista de casi cuarenta cofradías exclusivamente religiosas y diecisiete gremios, agrupados en mayores y menores, ${ }^{18}$ encontrándose los plateros en el segundo grupo. ${ }^{19}$

12 ALONSO BENITO, Javier, 2015, p. 19.

${ }^{13}$ El proceso de desintegración de 1813 a 1842 está exhaustivamente descrito en CRUZ VALDOVINOS José Manuel, 1983، p. $192-223$.

14 Sobre su figura, véase GARCÍA CORTÉS, Carlos, 2003.

15 BARRIOCANAL LÓPEZ, Yolanda, 1996, p. 131.

${ }^{16}$ El cargo de marcador de plata y oro en España fue creado por una real pragmática de los Reyes Católicos en el año 1488. Los marcadores, encargados de certificar la calidad del material, eran designados por el Concejo y tenían carácter fedatario público. Cuando recibían una pieza debían realizar las pruebas necesarias para certificar la ley de la plata y permitir su comercialización, extrayendo una viruta del metal con un buril. Este procedimiento dejó en muchas piezas lo que hoy conocemos como marca de burilada (FERNÁNDEZ, Alejandro; MUNOA, Rafael; RABASCO, Jorge, 1984, p. 47-48). Esta pragmática también estableció la ley de la plata, de once dineros y cuatro granos, lo que tuvo vigencia hasta 1730 (CRUZ VALDOVINOS, José Manuel, 1999, p. 526). Aunque marcador -que controlaba la calidad-y contraste -que controlaba la cantidad y el peso- eran dos cargos originalmente separados y así referidos en las pragmáticas, en la mayor parte de los casos el cargo correspondía al mismo platero y en Santiago no tenemos constancia de que estuviesen separados en ningún momento (DÚO RÁMILA, Diana, 2014, p. 192).

17 Sobre las medidas proteccionistas del gremio en épocas concretas, véase PÉREZ VARELA, Ana, 2017 y 2018).

${ }^{18}$ Fue publicado por RODRÍGUEZ GONZÁLEZ, Ángel, 1986, p. 463-473; aunque la clasificación de los gremios ya había sido comentada por BARREIRO MALLÓN, Baudilio, 1976, p. 122-124, sin transcribir el documento. Los gremios mayores eran cuatro: San Julián (herreros); Nuestra Señora de la O (sastres); Santo Tomás (canteros y carpinteros); y Nuestra Señora de la Encarnación (zapateros). Los gremios menores eran: San Benito (cereros); San Juan Bautista (alquiladores); San Bartolomé (horneros, pasteleros y cocineros); Santa Polonia (cordoneros y calceteros); San Mauro (sillateros y talabarteros); San Pedro (armeros y espaderos); San Cosme y San Damián (barberos y sangradores); Nuestra Señora de la Anunciación (tablajeros); Dulce Nombre de Jesús (tejedores); San Sebastián (azabacheros); San Eloy (plateros); y Nuestra Señora de las Nieves (mercaderes).

19 Sobre los plateros, el citado informe dice: "Cofradía de San Eloy, en dicha santa iglesia, que sirven los plateros. Constituciones aprobadas por el ordinario en el año de 1604, y en el 1746 por la ciudad. Pagan de entrada cada deprendiz 10 libras de 
El segundo documento data de poco después y es aquel que inventarió todas las cofradías y gremios de la ciudad, presentado en consistorio por el regidor Francisco Losada Ulloa en 1782. Se trata de un informe en el que se insistió en la importancia de realizar un seguimiento exhaustivo de las ordenanzas por las que se regían los gremios compostelanos y velar por su cumplimiento, nombrando un "director protector" para cada uno de los gremios mayores. ${ }^{20}$

El tercer documento son las propias ordenanzas del gremio de San Eloy de $1786,{ }^{21}$ que vinieron a ser la respuesta al susodicho informe pedido por el conde de Aranda, y siguieron, a grandes rasgos, las ordenanzas generales para las platerías de Madrid que Carlos III había establecido en 1770, en afán por controlar a los gremios de forma centralizada. ${ }^{22}$ Sabemos, especialmente por el estudio de los pleitos, que las condiciones para ingresar en el gremio y ejercer el oficio eran cada vez más duras y restrictivas, y que en muchos casos eran incumplidas por los propios asociados en un ambiente fuertemente marcado por el hermetismo y el proteccionismo. ${ }^{23}$ De hecho, fue el propio Concejo en 1775, y no los artífices, el que solicitó la redacción de unas nuevas ordenanzas ya que era el gremio de los plateros "el que conocidamente tiene más que reformar, pues de su mal método resultan inconvenientes y perjuicios visibles" ${ }^{24}$

En este documento se estableció una directriz reformista muy interesante, que instauró la obliga- toriedad a los aprendices de asistir diariamente a la escuela de dibujo de la Sociedad Económica. Esto supuso un impulso ilustrado a la platería de Santiago, pasando, aunque fuese en una parte pequeña del proceso, del control arbitrario de los maestros al contexto reglado de las Academias. Hasta entonces, la platería se había mantenido enmarcada exclusivamente dentro de un contexto de transmisión del conocimiento en un sentido gremial tradicional. ${ }^{25}$

El cuarto documento es un informe del Concejo remitido al Intendente de Galicia en 1815, donde la corporación municipal todavía calificaba de "antiguallas" a los gremios y sus ordenanzas, quejándose de su carácter de cofradía religiosa más que de unidad de producción artesanal. El texto instó a una reelaboración de las ordenanzas en base a los criterios de personas ilustradas e instruidas en la materia, donde se contemplasen disposiciones sobre "educación, aprendizaje, exámenes, marcas, policía, fomento, certámenes, premios, montepíos, etc."; y añadió: "nada de esto hay que buscar en los miserables folletos gremiales de esta ciudad: todo es menester crearlo de nuevo". ${ }^{26}$

Compostela, a la que Pose Antelo llamó "la ciudad artesana por excelencia", ${ }^{27}$ se resistió al cambio conservando ciertos rasgos de típicos del sistema gremial. Esto queda evidenciado por la marcada endogamia familiar en los talleres de oficios artísticos como pintores, doradores, imagineros, escultores, tallistas, doradores, azabacheros, joyeros o

Cera y de cofrade 150 reales, y tiene una función cada año que costea el mayordomo y le abonan para ella 6 libras de cera y gastará 100 reales. Asiste a las procesiones de Corpus y Jueves Santo, en cada una con seis hachas". Archivo Histórico Universitario de Santiago (en adelante AHUS). Consistorios. 1771 (AM 232), ff. 65r-74v.

20 AHUS. Consistorios, 1782 (AM 251), ff. 160r-161v; y 1783 (AM 253), ff. 71r-71v. Pérez Costanti publicó en prensa en 1918 la transcripción y un breve comentario al informe en: Diario de Galicia, 7 de abril de 1918, 1; texto recogido también en sus Notas Galicianas: PÉREZ COSTANTI, Pablo, 1933, p. 199-218.

21 Tenemos noticia de cuatro ordenanzas del gremio de San Eloy. Las de 1604 y 1746 sólo las conocemos por el documento posterior pedido por el conde de Aranda (1771), mientras que las de 1682 fueron presentadas en consistorio (AHUS. Consistorios, 1683 [AM], f. 85v), pero no se conserva el texto. Las de 1786 sí las conservamos y nos dan muchos datos sobre el funcionamiento del gremio a finales del siglo XVIII. Fueron publicadas y comentadas por Barriocanal López (BARRIOCANAL LÓPEZ, Yolanda, 1993-1994, p. 149-156).

22 Estas están comentadas y analizadas de forma exhaustiva en CRUZ VALDOVINOS, José Manuel, 1983, p. 155-183.

23 BARRIOCANAL LÓPEZ, Yolanda, 1993-1994, p. 150.

24 AHUS. Consistorios, 1775 (AM 239), f. 95.

25 Barreiro Mallón estableció unas pautas básicas comunes a todos los gremios compostelanos que más o menos debieron mantenerse vigentes de los siglos XV al XVIII: el aprendiz pagaba al maestro -con dinero, especie o trabajo doméstico-mientras tenía lugar su aprendizaje. Esta cantidad, así como la duración de contrato, tendió a subir con el tiempo, en un gesto por parte del gremio de endurecer la entrada de aspirantes y reducir el número de agremiados. Los maestros se hacían cargo de la manutención, vestido y calzado de los aprendices, que pasaban a vivir con ellos. Una vez terminado el aprendizaje, el aspirante presentaba solicitud de examen al Concejo, quien disponía la prueba, supervisada por el veedor del gremio y dos maestros. Ya aprobado, el artífice podía ingresar en la cofradía y abrir una tienda (BARREIRO MALLÓN, Baudilio, 1990, pp. 136137). Este sistema de examen y consecución del título fue el generalizado en toda España por la Real Pragmática de Carlos V de 1552 (REMUÑ́́N FERRO, Manuel, 1983, 113).

26 Cita extraída de PÉREZ COSTANTI, Pablo, 1933, p. 218.

27 POSE ANTELO, José Manuel, 1992, p. 114. 
plateros. Estos profesionales mantuvieron de forma habitual un local fijo donde trabajaban y vendían sus piezas, es decir, donde disponían su obrador y su tienda, sustentando unos núcleos familiares durante generaciones que siguieron marcando las pautas del aprendizaje del oficio. Solo hacia finales del siglo XIX, la consolidación de la Escuela de Dibujo y el establecimiento en 1888 de la Escuela de Artes y Oficios contribuyó a institucionalizar y profesionalizar el campo de los trabajos artísticos. ${ }^{28}$ Con estos organismos se desintegró la exclusividad de transmisión del conocimiento de los gremios.

En Santiago no se llevó a cabo ninguna experiencia de tipo institucional como la fábrica Martínez, de corte industrial y con una ambición de distribución a gran escala, manteniéndose los obradores compostelanos fieles a las técnicas y al sentido de producción tradicional. Sin embargo, la llegada a la ciudad de arquitectos formados en la Academia abrió un nuevo capítulo en los requisitos de formación de los artistas, exigiéndoseles una mayor preparación y conocimiento y una formación académica y científica. ${ }^{29}$ El sistema tradicional impedía a los agremiados el alcanzar algún grado de nobleza o gozar de los privilegios de las Bellas Artes, que los artistas llevaban reclamando desde hacía siglos. ${ }^{30}$ La desintegración del gremio permitió que emergiesen unos creadores más próximos al profesional liberal, o artista independiente, que al maestro gremial o artista agremiado. ${ }^{31}$

Asimismo, los gremios perdieron paulatinamente sus privilegios de autolegislación. Se disipó su legitimación por parte del Concejo y todas las normas corporativas contempladas en sus estatutos dejaron de tener vigor. Ya no era necesario, por ejemplo, pagar una cuota de entrada para ingresar en el gremio, o cumplir con una serie de obligaciones y requisitos para abrir una tienda. Con la liberalización del trabajo desapareció el excesivo proteccionismo, la prohibición de actuación de los extranjeros, el control total sobre la materia prima y el monopolio del oficio. De esta forma se desintegró su parte legislativa.

Durante el siglo XIX se siguieron manteniendo ciertos rasgos de potestad y permisividad por parte del Ayuntamiento compostelano para con los gremios, de forma residual e intermitente. Por ejemplo, en 1825 se elevó al Concejo una queja del platero de Noia, Francisco Crespo, acerca de los artífices que ejercían el oficio sin estar autorizados. ${ }^{32}$ Eso demuestra que el control consistorial seguía existiendo, o que los plateros debían seguir presentando un título oficial legitimado por el gremio. También seguían regulándose visitas a las platerías por parte de veedores designados por el Concejo estableciéndose una mensual. ${ }^{33}$ Asimismo, siguió activa la preocupación por la incursión de artistas foráneos y se siguieron elevando quejas al cabildo municipal. Conservamos algunos documentos en los que el gremio de San Eloy se lamentó de la actuación en la ciudad de plateros cordobeses, solicitando que "no se les permita más detención en los pueblos que los días de ferias y mercados". El Ayuntamiento prohibió finalmente que permaneciesen en Compostela: "[que] los plateros cordobeses salgan en un término perentorio de esta capital y que solo quince días pueden venir y permanecer en las ferias del Apóstol" ${ }^{34}$

\section{Marcas y marcadores}

En 1805 los Ayuntamientos recibieron de la Real Junta de Comercio y Moneda ${ }^{35}$ un documento que estipulaba los derechos y aranceles de los contrastes por marcar la plata, además de instrucciones para llevar a cabo el marcaje de forma correcta. ${ }^{36}$ A pesar de este afán centralista a principios de siglo, conforme avanzó la centuria se dejó de marcar la plata en España de forma generalizada. Según

\footnotetext{
28 Sobre estas instituciones, respectivamente, véase FERNÁNDEZ CASTIÑEIRAS, Enrique; FOLGAR DE LA CALLE, María del Carmen, 2013; SOUSA, José; PEREIRA, Fernando, 1988.

29 Sirva como ejemplo la disputa entre 1799 y 1800 del primer arquitecto titulado en la Academia, Melchor de Prado Mariño, con Miguel Ferro Caaveiro, maestro de obras de la Catedral, de formación tradicional, acerca del puesto de arquitecto municipal. PÉREZ RODRÍGUEZ, Fernando, 2010, p. 178-202.

30 BRUQUETAS GALÁN, Rocío, 2010, p. 28.

${ }^{31}$ DALMASES BALAÑÁ, Nuria; GIRALT-MIRACLE, Daniel, 1985, p. 180.

32 AHUS. Consistorios, 1825 (AM 365), f. 263r.

33 AHUS. Consistorios, 1829 (AM 379), f. 152.

${ }^{34}$ AHUS. Consistorios, 1828 (AM 376), f. 384v; 1829 (AM 377), f. 208v; 1829 (AM 377), f. 321v; y 1829 (AM 377), f. 396v.

${ }^{35}$ La Real Junta de Comercio y Moneda fue creada por Felipe V en 1730 para controlar las transacciones de plata y oro. A partir de ese momento este órgano reguló los nombramientos de fiel contraste, estableciendo en 1752 un periodo de seis años prorrogable y sujeto a la presentación del título necesario hecho que encontramos materializado en los documentos consistoriales en Santiago en varias ocasiones (CEBREIROS ÁLVAREZ, Eduardo, 1999, p. 185).

36 SÁNCHEZ-LAFUENTE GÉMAR, Rafael, 1997, p. 145-147.
} 
Cruz Valdovinos, sobrevivieron apenas una decena de centros que realizaban esta práctica. ${ }^{37}$ Santiago debió de ser una de esas ciudades, a juzgar por las piezas conservadas y los documentos en los que el Concejo siguió designando marcadores oficiales, ya que el marcaje dependía de los poderes públicos y no de los gremios, ya desintegrados. Las marcas de marcador son frecuentes en la platería compostelana, así como los documentos referidos a los nombramientos.

En el primer tercio del siglo XIX contamos con varios memoriales de pretendientes al cargo de fiel contraste. Juan Manuel Sánchez ${ }^{38}$ fue nombrado para el puesto en 1794, pidiendo en 1800, seis años después, que se le reeligiese. ${ }^{39} \mathrm{~A}$ su renuncia en 1804 presentaron en consistorio memoriales para su sustitución Francisco Reboredo, ${ }^{40}$ Juan Antonio Piedra, ${ }^{41}$ Gregorio Rodríguez Montenegro ${ }^{42}$ y Ángel Castro, ${ }^{43}$ aunque finalmente se eligió a Jacobo Pecul por un periodo de seis años, ${ }^{44}$ designando a Reboredo como sustituto. Es la primera y única vez que tenemos constancia de un contraste sustituto. En 1817 pretendieron el cargo Tomás Landeira y José García, y acabó ocupándolo Fran- cisco Reboredo, ${ }^{45}$ a quien se le prorrogó en $1824 .{ }^{46}$ En 1825 el Ayuntamiento leyó un oficio "referente al establecimiento de fieles contrastes marcadores de plata y oro, reglas que observan y derechos que deben prescribir según el modelo del arancel que acompaña", 47 demostrando que aún se estaban regulando dichas disposiciones.

Con respecto al segundo tercio del siglo, en 1839 se elevó una petición al Concejo por parte de Antonio García Candal para que se le nombrase contraste. ${ }^{48}$ En el libro de cuentas de la parroquia de San Andrés Apóstol se le nombra como "fiel contraste" en 1860 al referirse a un pago por la cruz parroquial. ${ }^{49}$ Creemos este platero pudo ser marcador hasta su muerte en $1878 .^{50}$

Aunque no hemos hallado documentación consistorial al respecto sabemos, por la simple observación de las piezas, que Manuel Aller fue contraste de la ciudad por lo menos en el último cuarto del siglo XIX. ${ }^{51}$

Resulta muy significativa dentro de los anuarios de comercio que analizaremos con detenimiento, la inclusión del epígrafe "fiel contraste de oro y

37 CRUZ VALDOVINOS, José Manuel, 1987, p. 149.

38 AHUS. Consistorios, 1794 (AM 277), 1794, ff. 243v-244r.

39 AHUS. Consistorios, 1800 (AM 286), ff. 51r y 194r.

40 Documentado en: BOUZA BREY, Fermín, 1962, p. 16.

${ }^{41}$ Memorial en: AHUS. Consistorios, 1804 (AM 298), f. 345v. Documentado en: COUSELO BOUZAS, José, 2005, p. 535; y BOUZA BREY, Fermín, 1962, p. 15.

${ }^{42}$ Documentado en: BOUZA BREY, Fermín, 1962, p. 16.

${ }^{43}$ Memorial en: AHUS. Consistorios, 1804 (AM 298), f. 361r. Documentado en: COUSELO BOUZAS, José, 2005, p. 151; y BOUZA BREY, Fermín, 1962, p. 16.

${ }_{44}$ AHUS. Consistorios, 1804 (AM 298), ff. 301r, 361r-361v. Jacobo Pecul Montenegro fue un célebre platero del panorama compostelano en las últimas décadas del siglo XVII y primeras décadas del siglo XIX. Sobre él, véanse COUSELO BOUZAS, José, 2005, pp. 497-509; BOUZA BREY, Fermín, 1964; y CANEDO BARREIRO, María, 2015. Pudo ser contraste hasta 1817, cuando encontramos el siguiente nombramiento. Sin embargo, la gran cantidad de obra que realizó y firmó hace difícil discernir qué piezas realizó y en cuáles actúa como marcador.

45 AHUS. Consistorios, 1817 (AM 337), f. 155r; 1718 (AM 338), f. 73v; y 1718 (AM 339), ff. 308r-308v. Encontramos el punzón REBO/REDO acompañado de la marca de localidad y/o de artífice en numerosas piezas de todo tipo en las parroquias compostelanas. Véanse publicadas en HERRERO MARTín, María Jesús, 1987, p. 93-94, 97, 104-105, 135-136, 141, y 169; FERNÁNDEZ, Alejandro; MUNOA, Rafael; RABASCO, Jorge, 1992, p. 212; LÓPEZ VÁZQUEZ, José Manuel, 1993, p. 196-199; y LARRIBA LEIRA, Mariel, 2000, p. 95 y 109.

${ }^{46}$ AHUS. Consistorios, 1824 (AM 360), ff. 150r y 277r; 1824 (AM 361), f. 278v.

47 AHUS. Consistorios, 1825 (AM 366), f. 215v.

48 AHUS. Consistorios, 1839 (AM 396), f. 71v. Encontramos el punzón A/GARCÍA como contraste en una gran cantidad de piezas de José Losada, así como asociada a otros plateros de la época como Seijo o Pérez. Véanse publicadas en FERNÁNDEZ, Alejandro; MUNOA, Rafael; RABASCO, Jorge, 1992, p. 212; LARRIBA LEIRA, Mariel, 2000, p. 973-974; PÉREZ VARELA, Ana, 2019, p. $140-141$.

49 HERRERO MARTín, María Jesús, 1987, p. 297.

${ }^{50}$ Hemos situado su muerte gracias a que las actas capitulares de la Catedral dan cuenta de que su obrador de platería queda libre por defunción. Archivo de la Catedral de Santiago (en adelante ACS). Actas Capitulares. Libro 79 (IG 634), cabildo del 29 de octubre de 1878, ff. 192v-193r.

51 Encontramos el punzón M/ALLER en varias piezas de Ricardo Martínez Costoya (como la reproducida en el sumario de esta revista, del Museo das Peregrinacions e de Santiago, Santiago de Compostela, por fotografía de la autora), Alejandro Bermúdez o Eduardo Rey. Véanse publicadas en FERNÁNDEZ, Alejandro; MUNOA, Rafael; RABASCO, Jorge, 1992; LARRIBA LEIRA, Mariel, 2000, p. 91; PÉREZ VARELA, Ana, 2019, p. 298. 
plata" como profesión en Compostela. En estos documentos se hace referencia al nombre del marcador de la ciudad en una fecha tan tardía como las tres primeras décadas del siglo XX. El cargo fue ocupado por Alejandro Bermúdez entre 1912 y 1922:52 para ser posteriormente ejercido por el obrador de la Viuda e Hijos de Bacariza, por lo menos hasta $1929 . .^{53}$

En algunas obras siguen incluyéndose también marcas de localidad. Según Bouza Brey, el punzón de Santiago de Compostela fue sucesivamente: una figura del Apóstol peregrino; una concha jacobea; el sepulcro de Santiago; y un cáliz con hostia y cruz; ${ }^{54}$ siendo la última la que corresponde al siglo XIX. Con respecto a los documentos consistoriales, la única vez que aparece mencionada es en 1818, cuando se dio licencia al contraste Francisco Reboredo para marcar las piezas "con la divisa del Sacramento y su apellido". 55

En el transcurso de nuestra investigación hemos observado que las pocas piezas que ostentan marca de localidad en el siglo XIX presentan este modelo del cáliz con la sagrada forma, u otra con la palabra SANTIAGO. Esta segunda variante solo la hemos encontrado referenciada por Artiñano y Galdácano en su catálogo de $1925,{ }^{56}$ que señaló la marca como un punzón compostelano del si- glo XIX, y por Fernández, Munoa y Rabasco que la documentaron en un pastillero anónimo en colección privada. ${ }^{57}$ Creemos que debió de ser posterior a la del cáliz. Es poco común y la conocemos solamente en tres piezas, de Ricardo Martínez Costoya, datadas ya en el tránsito del siglo XIX al XX. ${ }^{58}$

Aunque no es algo sistemático, las marcas de artífice son frecuentes en Compostela en el siglo XIX. Sin embargo, pensamos que este rasgo tiene que ver más con la propia intención del artista de firmar su obra que con certificar su calidad como parte de una medida gremial o consistorial. Seguimos encontrando, incluso en fechas muy tardías en la centuria, un triple sistema de marcaje con los punzones de marcador, ciudad y artífice, lo cual resulta extraordinario teniendo en cuenta que es complicado hallarlas incluso en épocas donde el marcaje tenía un cariz de obligatoriedad mayor. Lo encontramos en más de una decena de obras. ${ }^{59}$ Una de ellas se realizó para la Catedral, por lo que podemos apuntar que las piezas de la fábrica también eran llevadas al contraste de la ciudad en algunas ocasiones.

Otro rasgo habitual en la segunda mitad del siglo XIX y primeras décadas del siglo XX son las marcas de calidad, concretamente la de IID, que indicaba la ley de la plata, de once dineros, o 916,16

52 Los años 1913 y 1914 se encuentran incompletos y no aparece la provincia de A Coruña. En el resto, siempre encontramos referido el cargo excepto en 1915. Para citar esta publicación, se hace referencia al número de rollo de microfilm dentro de la serie BAILLY-BAILLIĖRE Charles; RIERA, Eduardo (1912), rollo 3, p. 2387; (1916), rollo 16, p. 2644; (1917), rollo 21, p. 2685; (1918), rollo 26, p. 2832; (1919), rollo 31, p. 2938; (1920), rollo 36, p. 3049; (1921), rollo 42, p. 3068; y (1922), rollo 47, p. 3032.

53 BAILLY-BAILLIÈRE Charles; RIERA, Eduardo (1923), rollo 52, p. 3117 (1924), rollo 58, p. 3129 (1925), rollo 63, p. 3174 (1926), rollo 69, p. 3459 (1927), rollo 76, p. 3583 (1928), rollo 82, p. 3772; y (1929), rollo 89, p. 2149.

54 BOUZA BREY, Fermín, 1962, p. 4. Antes, ARTIÑANO Y GALDÁCANO, Gervasio de, 1925, p. 87, había publicado las de la urna (siglo XVII), la concha (siglos XVIII) y la marca SANTIAGO (siglo XIX).

55 AHUS. Consistorios, 1818 (AM 338), f. 73v.

${ }^{56}$ ARTIÑANO Y GALDÁCANO, Gervasio de, 1925, p. 87.

57 FERNÁNDEZ, Alejandro; MUNOA, Rafael; RABASCO, Jorge, 1992, p. 210-212.

${ }^{58}$ Nos referimos a un acetre del Museo de las Peregrinacións e de Santiago dos lámparas de la Catedral y una bandeja subastada en Madrid en 2013. Ninguna está datada mediante documentación, por lo que no podemos aproximar una delimitación cronológica PÉREZ VARELA, Ana, 2019, p. 298.

59 Contrastadas por Sánchez tenemos: una cruz de Jacobo Pecul en la Colegiata de Santa María do Campo (LOUZAO MARTíNEZ, Xosé Manuel, 1993, p. 88-89); un juego de candeleros de Reboredo (1795) en la catedral de Salamanca; un atril de José Noboa (1799) en colección privada (FERNÁNDEZ, Alejandro; MUNOA, Rafael; RABASCO, Jorge, p. 1992, 212); un cáliz de Bermúdez en San Bieito do Campo y una naveta de Méndez en la misma iglesia; (HERRERO MARTín, María Jesús, 1987, p. 114 115, y 135-136, respectivamente). También podría relacionarse con él un juego de cruz y candeleros en la susodicha Colegiata de atribución dudosa (LOUZAO MARTínEZ, Xosé Manuel, 1993, p. 83-84). Contrastadas por Reboredo tenemos: una cuchara de Jacinto Fuentes y una escribanía de Ramón Aller, ambas en colección privada (FERNÁNDEZ, Alejandro; MUNOA, Rafael; RABASCO, Jorge, p. 212); así como un cáliz, también de Fuentes, en San Bieito (HERRERO MARTín, María Jesús, 1987, p. 125126); y otro cáliz y una naveta de Bermúdez en San Martiño Pinario (LARRIBA LEIRA, Mariel, 2000, p. 95 y 109. Contrastadas por García contamos con varias piezas de José Losada, como unas vinajeras en San Bieito (HERRERO MARTíN, María Jesús, 1987, p. 140); un cáliz en la Catedral (PÉREZ VARELA, Ana, 2016, p. 520-521); y una bandeja en colección particular (FERNÁNDEZ, Alejandro; MUNOA, Rafael; RABASCO, Jorge, p. 212). Contrastadas por Aller tenemos tres piezas de Ricardo Martínez (PÉREZ VARELA, Ana, 2019, p. 298); así como una bandeja en San Martiño Pinario de Eduardo Rey (LARRIBA LEIRA, Mariel, 2000, p. 91); y una crismera y vinajeras de Bermúdez en colección privada (FERNÁNDEZ, Alejandro; MUNOA, Rafael; RABASCO, Jorge, 1992, p. 212). 
milésimas. Su aparición es especialmente notable en las piezas de Ricardo Martínez Costoya, donde la encontramos de forma frecuente acompañando a su marca de artífice por lo menos en veintidós piezas. $^{60}$ Esto denota un interés personal por dejar impresa en la pieza la marca que certifica la calidad del material de la obra.

Más complicado resulta encontrar marcas cronológicas en las obras, aunque existieron, como certifican algunas recogidas en los catálogos. Todas las que hemos hallado son piezas relacionadas con Juan Manuel Sánchez, y no tenemos constancia de que otro contraste emplease marcas cronológicas. Solo de 1796 se conocen siete obras marcadas por este. ${ }^{61}$

\section{Los artífices}

\subsection{Los anuarios de comercio}

Uno de los documentos en los que podemos encontrar registrada la actividad profesional de los plateros de finales del siglo XIX y principios del siglo XX son los distintos tipos de anuarios de comercio con información comercial que se conservan en la Biblioteca Nacional de Madrid. Estos siguen la estructura de los documentos de este tipo que proliferaron en Europa y Estados Unidos en la segunda mitad del siglo XIX, en paralelo al desarrollo de la sociedad industrial y la mentalidad capitalista. El más importante en España de finales del siglo XIX fue el Anuario-Almanaque de Comercio editado desde 1879 por Carlos Bailly-BaiIlière, donde se registraban todas las personas que integraban las administraciones públicas y todo aquel que tuviese un oficio tanto en España como en las posesiones de Ultramar. Por otra banda tenemos el Anuario Riera, de idéntico planteamiento que comenzó a publicarse en 1896 como Guía General de Cataluña, y se amplió al resto de España en 1901. Ambas publicaciones se unieron en un documento conjunto a partir de 1911. Tuvimos la oportunidad de trabajar con estas publicaciones en la Biblioteca Nacional de Madrid, tras lo cual pudimos extraer las siguientes conclusiones:

Los anuarios se elaboraban, como cabría esperar, mediante corresponsales en las capitales provinciales que recogían datos de las instituciones y profesionales, comerciantes e industriales. Tenemos por lo tanto una ingente cantidad de información re- copilada, lo que motivó, como es lógico, que cada año se copiase de forma literal el año anterior, añadiendo los nombres nuevos y eliminando los retirados de la profesión o fallecidos. Esto hizo que en algunos casos se repitiesen defectos de grafía que se perpetuaron en sucesivos números. En el caso de Santiago, por ejemplo, encontramos apellidos referidos a la misma persona escritos de forma diferente -tales como Legrand/Legrande o Bacariza/Baqueriza-, y lo mismo sucede con las ubicaciones.

En los anuarios observamos oficios que tienen ver con el de platero, dependiendo de cada texto. Así, para el Bailly-Baillière son: "batidores de oro y plata", "broncistas", "dorador a fuego" y "joyeros" de 1881 a 1888; añadiéndose la categoría de "plateros" desde 1894, y desapareciendo la categoría de "dorador a fuego" en 1898. En el caso del Riera, contamos con las categorías de "batidores de oro y plata", "broncistas", "joyeros" y "plateros"; mientras que en el Bailly-Baillière y Riera los grupos recogidos son: "batidores de oro y plata", "broncistas", "joyerías", y "fábrica de medallas". Esta última categoría no aparece en los otros anuarios y está ocupada de forma exclusiva de 1912 hasta 1929 por Jesús Paz. A estos cuatro grupos viene a sumarse en 1926 la de "repujador de oro y plata".

En el sentido estricto del término, un batidor de oro y plata era el encargado de preparar láminas de pan de oro y plata para dorar o platear, y no tenía porqué dedicarse a hacer piezas. Sin embargo, podemos observar que en estos primeros años no existió la categoría de "platero" y todos ellos reciben esta denominación. Cuando en 1894 apareció la categoría "platero", no se eliminó la de "batidor de oro y plata", y es más, los plateros compostelanos como Ricardo Martínez siguieron apareciendo en la segunda, mientras que la primera solo está ocupada por José Lorenzo. Incluso, los nombres se repiten en varias categorías distintas cada año. El propio Lorenzo aparece ese mismo año en la de "joyeros" y "dorador a fuego".

En el siguiente documento disponible, el de 1897, la mayoría de los nombres de la categoría "batidor de oro y plata" se repiten en la de "platero": Alejandro Bermúdez, Eduardo Rey Villaverde, Manuel Aller, Ramón Corral, y Ricardo Martínez. Sin embargo, algunos siguen identificándose sólo en la primera categoría: Andrés Legrande, Jesús Paz

60 PÉREZ VARELA, Ana, 2019, p. 297.

${ }^{61}$ Las obras pueden verse publicadas en MOLIST FRADE, Beatriz, 1986, p. 50; FERNÁNDEZ, Alejandro; MUNOA, Rafael; RABASCO, Jorge, 1992, p. 212; LARRIBA LEIRA, Mariel, 2000, p. 85, 93 y 94; y KAWAMURA KAWAMURA, Yayoi; SÁEZ GONZÁLEZ, Manuela, 1999, p. 39 y 74, y cat. 188-189. 


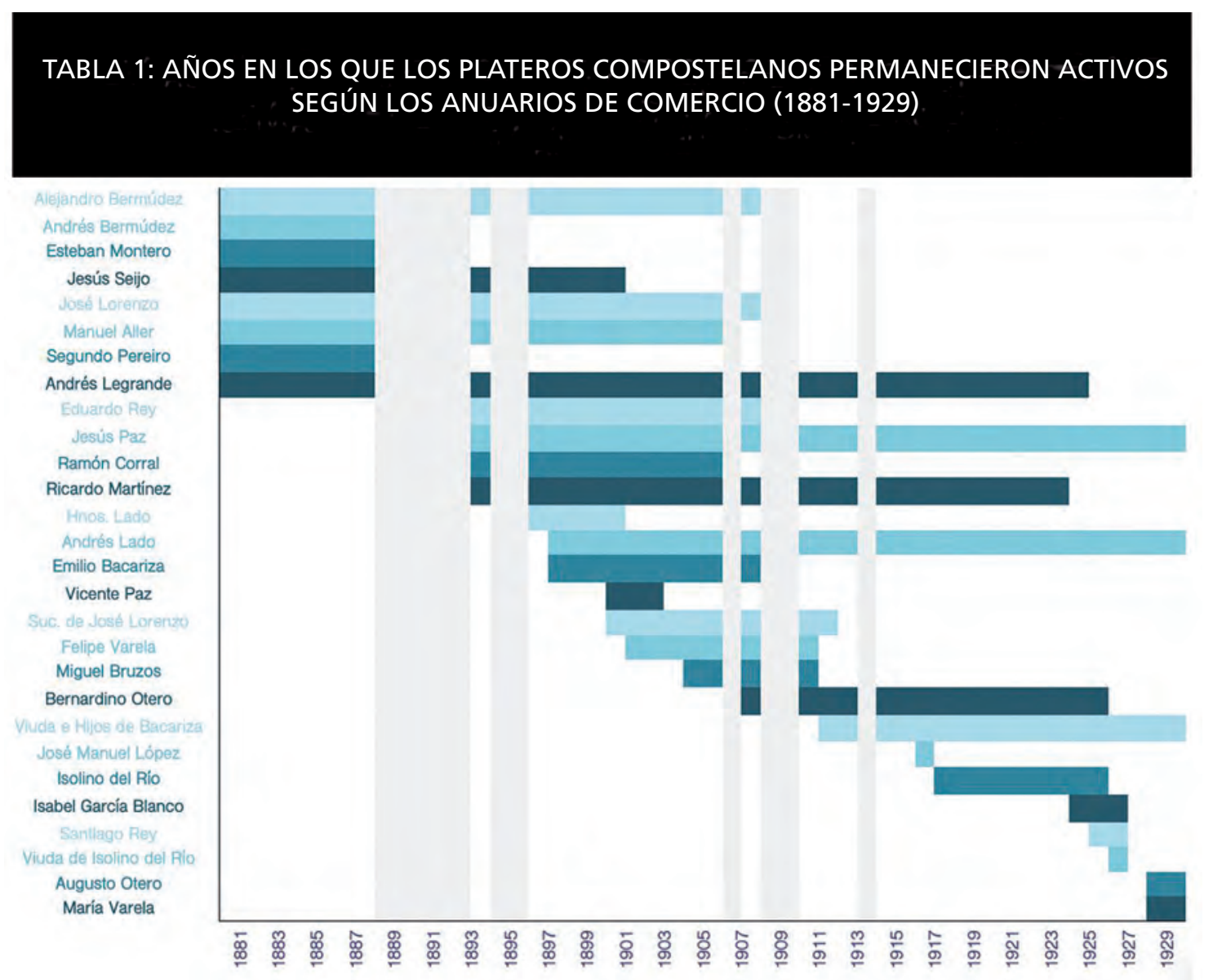

Fuente: elaboración propia a partir de los datos recogidos en los Anuarios de Comercio: BAILLY-BAILLIÈRE, Charles, 1881-1901; RIERA, Eduardo, 1901-1911; BAILLY-BAILLIÈRE, Charles; RIERA, Eduardo (1912-1929).

y Jesús Seijo; y otros solo en la segunda: Hermanos Lado, José Lorenzo y Vicente Paz. Continúan apareciendo en ambas categorías durante toda la cobertura cronológica de la publicación, con algunas apariciones y desapariciones temporales, aunque según nuestra experiencia en la platería de finales del siglo XIX en Santiago, todos estos nombres pueden considerarse plateros. Todo esto demuestra que la denominación del oficio fue imprecisa, especialmente en este tipo de fuente.

A pesar de estas imprecisiones, la ordenación de esta información nos permite tener una visión bastante aproximada del tiempo en el que cada platero permaneció activo en Compostela. Con el fin de visualizarlo mejor, hemos elaborado una tabla [Tabla 1] en la que cada platero está recogido con su etapa cronológica de actividad, teniendo en cuenta los periodos de los cuales no se conocen datos, señalados en gris. Han sido ordenados en de forma cronológica para así tener una mejor visión de los distintos nombres que se van suce- diendo, permitiéndonos afirmar que cada pocos años se incorporaban plateros nuevos a la nómina compostelana. Algunos de ellos mantuvieron carreras sólidas y permanentes en el tiempo, mientras que otros nombres desaparecieron tras pocos años de actividad.

Esta nómina de plateros nos permite corroborar dos cuestiones que tradicionalmente se han repetido en los oficios de carácter gremial en cualquier época y cualquier territorio. Nos referimos por un lado a la endogamia, ejemplificada por los apellidos Bermúdez, Bacariza, Lado, del Río, Otero, Rey, Lorenzo, o Varela; que indica la tendencia gremial general de transmitir el conocimiento en el obrador familiar. En algunos casos, se prefiere la denominación "sucesores de", como acontece con los hijos de José Lorenzo, lo que puede indicarnos que el obrador deseaba mantener la fama que se había granjeado el padre.

Por otro lado, también podemos observar la predisposición habitual a que una vez fallecido el 
platero, su viuda se hiciese cargo del obrador familiar. Su implicación laboral dependía de cada caso, conociéndose ejemplos de siglos anteriores en los que la mujer ostentaba solo la titularidad del obrador, asociándose con otros plateros; pero también ocasiones en los que la propia mujer ejercía el oficio. ${ }^{62}$ En algunos casos aparece sola y en otros con los hijos que habían heredado el trabajo. En esta cronología hemos de destacar a la viuda de Isolino del Río, activa los últimos años recogidos (1927-1929), así como la familia de Emilio Bacariza, que aparece como Viuda e Hijos (19111929), aunque paralelamente los dos últimos años (1928-1929) se registra también a María Varela, la viuda, de forma independiente.

Asimismo, los anuarios de comercio son interesantes para ubicar los obradores en el plano urbano, aunque con muchas imprecisiones derivadas de la casuística ya mencionada de estos documentos. Los plateros se agruparon en las inmediaciones de la praza de Praterías, aunque encontramos tres denominaciones distintas. La primera es "bajos de la Catedral", que se refiere inequívocamente a los locales que la fábrica alquilaba a los plateros ubicados en la parte baja del claustro, que ocupa el frente occidental de la susodicha plaza. La segunda es "rúa Fonseca", que se refiere al obrador de Ricardo Martínez, el único que tenía dos puertas, una hacia Praterías y otra hacia dicha calle; ${ }^{63}$ y por último, la propia designación de "praza de Praterías", que creemos, se refiere a los locales de los frentes oriental y meridional de la plaza, que ya no estarían en los bajos catedralicios. Esta tercera denominación pasó a ser, a partir de 1915, la "praza do cardeal Martín de Herrera". ${ }^{64}$ En este núcleo se ubicaron los obradores de Alejandro y Andrés Bermúdez, Esteban Montero, Jesús Paz, Ramón Corral,
Manuel Aller, Ricardo Martínez, Bernardino Otero y Eduardo Rey. ${ }^{65}$

Otro núcleo muy importante de plateros se localizó a lo largo de la rúa do Vilar, que parte de Praterías. Allí aparecen los nombres de Rafael Otero, los Hermanos Lado -entre ellos Andrés, en obrador aparte-, José Lorenzo y sus sucesores -entre ellos Miguel Bruzos-, Andrés Legrande, Emilio Bacariza -y posteriormente su viuda María Varela-, Francisco Refojo, Jesús Paz, y Bernardino Otero. ${ }^{66}$

También registramos nombres de plateros en otras zonas como rúa do Preguntorio -Santiago Rey y Andrés Legrande- ${ }^{-67}$ praza do Toural o rúa dos Bautizados ${ }^{68}$-Felipe Varela y posteriormente su sucesor Constante-; praza de Cervantes -Isolino del Río y posteriormente su viuda-; rúa de San Roque -Isabel García Blanco-; y rúa Caldeirería -Jesús Seijo y Segundo Pereiro-.

En esta última calle se asentaron, como corresponde a su etimología, las sagas de caldereros y broncistas como los Núñez -Nicolás y Manuel-, y Segade -Santiago y Juan-. Otros profesionales de este tipo de ubicaron en rúa Rego de Auga -José López y Manuel Montero-; rúa de San Clemente -Federico Turnó-; e rúa do Inferniño de Arriba -Ramón Maseda-. Por su parte, los joyeros que aparecen en los anuarios son los mismos que los plateros, con la excepción de Vicente Romero Mimo y Juan Rodríguez Álvarez, registrados solo como joyeros, y ambos ubicados en rúa Caldeirería.

También debemos recalcar que los anuarios suponen una gran fuente de información publicitaria de época, incorporando anuncios comerciales, muchos de los cuales sobresalen por su diseño o carácter llamativo. Sin embargo, en el caso de los plateros com-

62 DÚO RÁMILA, Diana, 2014, p. 209-216.

63 PÉREZ VARELA, Ana, 2019, p. 161-162.

64 Pese a que Rodríguez González afirmó que a la praza de Praterías se le otorgó esta denominación con motivo del ochenta cumpleaños del prelado (RODRÍGUEZ GONZÁLEZ, Ángel, 1999, p. 30), el nombre fue cambiado en el acto de colocación de la placa homenaje al cardenal en dicha plaza, en 1915, por las bodas de plata de su prelatura (Boletín Oficial del Arzobispado de Santiago, 31 de diciembre de 1915, p. 11).

${ }^{65}$ Aparece registrado en tres ubicaciones, contradictorias en algunos años entre los distintos anuarios. Bailly-Baillière lo sitúa en rúa do Preguntorio de 1894 a 1898; y en rúa dos Loureiros de 1899 a 1911. Riera lo ubica en los bajos de la Catedral de 1899 hasta 1908, ubicación que mantiene el anuario reunido, de 1915 hasta 1924. El que creemos su sucesor, Santiago Rey, en cambio, se instaló en la primera de sus ubicaciones, en rúa do Preguntoiro.

${ }^{66}$ Aparece registrado primero en rúa do Vilar, 2 (1906); para posteriormente ubicarse en praza de Praterías (1908-1909), obrador del que se hizo cargo su sucesor Augusto Otero (1927).

${ }^{67}$ Aparece registrado en rúa do Preguntoiro desde 1894, pero en 1899 pasa a aparecer en una doble ubicación, manteniendo ese obrador como batidor de oro y plata; y otro en rúa do Vilar como platero. A partir de 1902 aparece solo en rúa do Vilar. Cabe la posibilidad de que los anuarios de 1899 a 1901 estuviesen manteniendo la ubicación anterior por copia, y que se hubiese mudado ya a un único obrador.

${ }^{68}$ Aparece ambas denominaciones indistintamente, pero creemos que se trata de la misma ubicación ya que es una de las calles que desembocan en dicha plaza. 
postelanos no suele ser frecuente. En el anuario Bailly-Baillière solo aparece un platero destacado, Ricardo Martínez, en 1909. Se trata de un sobrio anuncio sin imágenes donde se resalta la obtención por parte del artífice de medallas de oro y plata en exposiciones. ${ }^{69}$ En alguna otra ocasión encontramos a un platero remarcado tipográficamente, con una fuente de mayor tamaño destacada sobre el resto, pero sin llegar a constituir un anuncio. ${ }^{70}$

\subsection{Las matrículas industriales}

Existen estudios acerca de los primeros registros mercantiles en España y el papel que han jugado en la reconstrucción histórica de las estructuras laborales. ${ }^{71}$ Para el caso de Santiago, las matrículas industriales del archivo municipal se encuadran dentro de las consecuencias del Código de Comercio de 1885, que estableció un Registro Mercantil en cada capital de provincia, que registrase todos los propietarios con carácter potestativo, y todas las sociedades con carácter obligatorio. ${ }^{72}$ Fueron analizadas por Pose Antelo para elaborar sus consideraciones sobre la estructura laboral de Santiago en la primera etapa de la Restauración (18751902) ${ }^{73}$ texto en el cual el historiador ya apuntó al interés que suscitaban estos documentos como fuente histórica.

Siguiendo el mismo procedimiento de análisis que hemos aplicado a los anuarios de comercio, podemos apreciar información muy similar como los nombres de los plateros y la ubicación de su obrador, lo que nos permite contrastar los datos de ambas fuentes. Asimismo, hemos elaborado una tabla con los mismos parámetros que la anterior aplica- da a los anuarios [Tabla 2]. La comparativa entre ambas tablas en el periodo cronológico coincidente, es ilustrativa de muchas contradicciones entre ambas fuentes. Las matrículas presentan más interrupciones en la carrera de los plateros, derivadas de aspectos económicos del ejercicio anual, mientras que los anuarios recogen los nombres ininterrumpidamente hasta su desaparición. Precisamente con respecto a la desaparición es donde encontramos mayores diferencias. Siempre suele registrarse con anterioridad en las matrículas que en los anuarios, en algunos casos con muchos años de diferencia. ${ }^{74}$

Por lo general, los nombres de los plateros recogidos en ambos documentos coinciden, con algunas excepciones. En las matrículas encontramos a Juan Rodríguez Álvarez, José Gómez, los Hermanos Hernández o Jesús Pérez, nombres no recogidos en los anuarios. $Y$ viceversa, José Lorenzo, Segundo Pereiro, o la viuda de Isolino del Río, no aparecen en las matrículas.

Las matrículas resultan más interesantes que los anuarios por dos motivos. El primero es que además de toda esta información antedicha, aportan datos acerca de la cotización de los plateros, es decir, la cuota de contribución anual que cada artífice debía de pagar al fisco. El segundo es que, derivada de esta contribución, existía una categorización de artífices en "clases", en la cual encontramos a todos los plateros compostelanos distribuidos en distintas denominaciones de oficio. Entre 1887 y 1891 aparecen los "plateros" en la clase 8 y los "engastadores de piedras falsas" en la clase $9 .{ }^{75}$ A partir de 1893, esos mismos plateros son elevados a la cate-

\footnotetext{
69 "R. Martínez / Orfebrería y repujados artísticos en plata. Premiado con medallas de oro y plata en varias exposiciones / Calle Fonseca / Santiago (Galicia)". Así se le menciona en BAILLY-BAILLIĖRE, Charles, 1909, p. 2305.

70 Nos referimos a José Lorenzo en 1898 (BAILLY-BAILLIÈRE, Charles, 1898, p. 1328); a Isolino del Río en 1918, donde también se destaca la obtención de premios por su trabajo: "Platería y Joyería / Isolino del Río / Primer premio en el certamen de la Liga de Amigos, 1915 / Construcción y restauración de objetos de arte / Especialidad en Repujados Artísticos / Cervantes, 11 / Santiago" (BAILLY-BAILLIĖRE, Charles; RIERA; Eduardo, 1918, rollo 26, p. 2836-2837); a los Hijos y Sucesores de Bernardino Otero; y a Santiago Rey, estos dos últimos en 1925 (BAILLY-BAILLIÈRE, Charles, RIERA, Eduardo, 1925, rollos 63-64, p. 31833184. Los Sucesores de Bernardino Otero repiten este tipo de anuncio en 1926 (BAILLY-BAILLIÈRE, Charles; RIERA, Eduardo, 1926, rollo 69, p. 3468).

71 Véanse, entre otros, ARRIBAS ÁlVAREZ, José Francisco, 1990; MARTín ACEÑA, Pablo, 1993; HERRERO PASCUAL, Ana María; MONTOJO MONTOJO, Vicente, 2002.

72 MONTOJO MONTOJO, Vicente, 2002, p. 233.

73 POSE ANTELO, José Manuel, 1989.

74 Por ejemplo, Emilio Bacariza desaparece de las matrículas en 1900, mientras que de los anuarios lo hace en 1908-1910. Lo mismo sucede con Jesús Seijo, 1893 contra 1901; o Ramón Corral, 1899 contra 1906-1907. Más exagerada resultan las diferencias de Andrés Legrande, 1907 contra 1925; o Eduardo Rey, 1890 contra 1924. Hay algunas excepciones en las que sucede al revés, y desaparecen antes en los anuarios que en las matrículas, pero con poca diferencia cronológica. Nos referimos a Manuel Aller, que desaparece en las matrículas en 1910 y en los anuarios en 1906-1907; o Alejandro Bermúdez, 1913 contra 1907-1910.

75 AHUS. Matrícula industrial, $1887-1891$ (AM 1760), 1887-1888, ff. 22r-22v y 23r; $1888-1889$, f. 22 r y 23r; $1889-1890$, f. 20r y f. 21 r; y $1890-1891$, ff. $22 v$ y $23 v$.
} 


\section{TABLA 2: AÑOS EN LOS QUE LOS PLATEROS COMPOSTELANOS PERMANECIERON ACTIVOS SEGÚN LAS MATRÍCULAS INDUSTRIALES (1887-1927)}

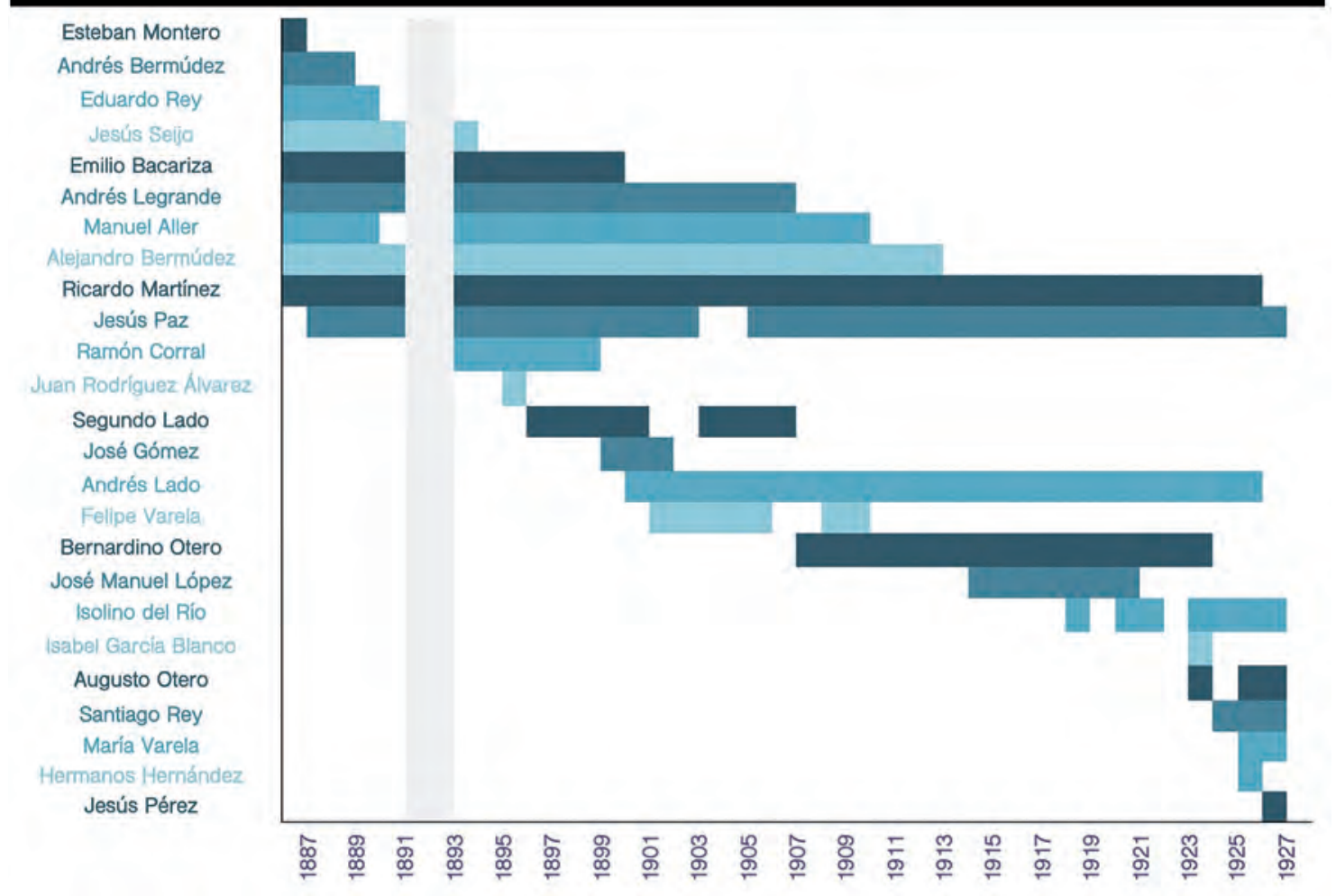

Fuente: elaboración propia a partir de los datos recogidos en las matrículas industriales del AHUS de 1887 (AM 1735 ) a 1927 (AM 1803).

goría de "orífice platero" en la clase 1, con una cotización mucho mayor. Los engastadores de piedras falsas son elevados a la clase $7 .^{76}$ En 1897 además de estas dos, aparece la categoría de "platero compositor de objetos de oro y plata", en la clase 6. ${ }^{77}$ En 1900 aparece la categoría de "esmaltador y engastador de piedras finas" en la clase $4 .{ }^{78}$

Estas diferentes denominaciones con sus correspondientes cotizaciones, mayores o menores según la clase, resultan extrañas, ya que la totalidad de nombres recogidos en estos epígrafes son plateros, inde- pendientemente de que se dedicasen también a esmaltar o engastar piedras. ${ }^{79}$ Tampoco comprendemos la diferencia entre orífice platero y platerocompositor de objetos de oro y plata. En un principio podría referirse a que en la segunda denominación estos artífices solo se dedicaban a componer piezas, lo cual resulta incompatible con la realidad. Además, algunos de los nombres cambian de denominación según los años, normalmente ascendiendo, pero existen casos en los que estos plateros se degradan de clase, como es el caso de Ri-

${ }^{76}$ AHUS. Matrícula industrial. 1893-1894 (AM 1761), ff. 19v-20r y 22v.

77 AHUS. Matrícula industrial. 1896-1897 (AM 1764), ff. 22r, 23v y 24v.

78 AHUS. Matrícula industrial. 1899-1900 (AM 1767), ff. 24v, 25v, 26v y 27v.

79 Las citadas ordenanzas de Carlos III de 1771 habían establecido la figura del «agregado a la Platería», que abarcaba profesiones como forjadores, tiradores, hiladores de oro y plata, afinadores, vaciadores, lapidarios y abrillantadores de piedras finas. Sin embargo, las propias disposiciones indicaban que no tenían permitido ejercer como plateros (CRUZ VALDOVINOS, José Manuel, 1983, p. 159). En el caso de Santiago, todos son plateros. 
cardo Martínez, que llegó a ser orífice platero en 1906 para luego volver a ser engastador de piedras finas en 1920 y hasta el final de su carrera. ${ }^{80}$

Un aspecto curioso es que ni los anuarios ni las matrículas recogen a la totalidad de los plateros compostelanos. Por ejemplo, el censo de 1885 indica un recuento de 51 plateros, ${ }^{81}$ mientras que el anuario registra menos de diez ${ }^{82}$ y la primera matrícula disponible, de 1887, censa nueve. ${ }^{83}$ Ignoramos si se trata de una cuestión de fama o importancia, aunque creemos que la cuestión gira en torno a este asunto, ya que los plateros registrados en anuarios y matrículas son los artífices de las piezas compostelanas conservadas hoy en día en museos y parroquias. Pensamos que el resto de plateros censados pueden referirse a oficiales y aprendices de los talleres de los maestros plateros, únicos recogidos en este tipo de documentos.

\section{Conclusiones}

El análisis de la bibliografía y las fuentes propuestas en este artículo, así como elementos del contexto histórico en los que no hemos podido detenernos -como el auge de las exposiciones de artes y oficios-, demuestra que los plateros de Santiago, aunque se alejaron paulatinamente de la organización corporativa colectiva gremial en reflejo de la situación que estaba teniendo lugar en España, siguieron manteniendo un sistema de organización individual basado en los mismos principios. Combinaron el aprendizaje en el sistema tradicional maestro-oficial-aprendiz en los obradores, con cierta apertura a las nuevas fórmulas educativas de corte académico. Su principal actividad fue en general el pequeño comercio para abastecer a las iglesias de la archidiócesis y la burguesía compostelana. No se desarrollaron en Compostela experiencias de corte industrial y a gran escala, que sí tuvieron lugar en otras partes de España, manteniéndose la platería compostelana como una actividad artesanal minorista.

Las fuentes consistoriales nos han permitido constatar que el Ayuntamiento siguió manteniendo cierto clima de permisividad con respecto a las disposiciones legislativas adoptadas por los propios gremios, y reservándose el derecho a nombrar al fiel contraste, un cargo que no dejó de ser público. Gracias a esta documentación hemos conseguido confeccionar una lista de los nombres de los marcadores de Santiago de Compostela con su cronología, haciendo posible datar una gran cantidad de piezas desde finales del siglo XVIII hasta principios del siglo XX que se conservan en Compostela con marca de fiel contraste.

Con respecto al grado de legitimidad de las fuentes comerciales en las que hemos basado nuestra investigación, creemos que los anuarios son un documento meramente informativo recogido, como ya hemos indicado, de forma imprecisa y repetitiva anualmente, y además, por iniciativa editora. Mientras, las matrículas son un documento gubernamental y tienen un sentido legal que implica que la información contenida, de no ser correcta, tendría consecuencias económicas. No obstante, las contradicciones observadas en ambos tipos de documentos nos indica que debemos acercarnos a ellos cautela, ya que su análisis demuestra ciertas imprecisiones, nombres que se repiten y plateros -en el sentido estricto del término- recogidos en otros epígrafes de oficios similares, como broncistas, joyeros o batidores.

Pese a estas puntualizaciones, constituyen una fuente interesante para acercarse a la reconstrucción de la nómina de un gremio olvidado por la historiografía en Compostela. Las investigaciones que estamos llevando a cabo en el momento demuestran la gran importancia que jugaron los plateros en el panorama artístico de la época, especialmente en las últimas décadas de la centuria, coincidiendo con el fructífero contexto que cristalizó tras la segunda inventio apostólica o el hallazgo por segunda vez de los restos de Santiago. A esperas de pulir algunos aspectos que nos permitan pautar las conclusiones al respecto de su importancia socioeconómica y artística, este primer artículo sienta las bases fundamentales de estudio a través de las fuentes documentales, rescatando del olvido los nombres de artistas que permanecen todavía esperando un estudio específico.

\section{Fuentes}

ACS. Actas Capitulares. Libro 79 (IG 634), cabildo del 29 de octubre de 1878, ff. 192v-193r.

AHUS. Consistorios, 1683. (AM), f. 85v; 1718 (AM 338), f. 73v; 1718 (AM 339), ff. 308r-308v; 1771 (AM 232), ff. 65r-74v; 1775 (AM 239), f. 95; 1782 (AM 251), ff. 160r161v; 1783 (AM 253), ff. 71r-71v; 1794 (AM 277), ff. 243v-244r; 1800 (AM 286), ff. 51r y 194r; 1804 (AM

\footnotetext{
80 PÉREZ VARELA, Ana, 2019, p. 157-159.

81 SOUSA, José; PEREIRA, Fernando, 1988, p. 31.

82 BAILLY-BAILLIÈRE, Charles, 1898, p. 1002-1003.

${ }^{83}$ AHUS. Matrícula industrial, 1887-1888 (AM 1760), ff. 22r, 22v y 23r.
} 
298), ff. 301r, 345v, 361r-361v y 361r; 1817 (AM 337), f. 155r; 1818 (AM 338), f. 73v; 1824 (AM 360), ff. 150r y 277r; 1824 (AM 361), f. 278v; 1825 (AM 365), f. 263r; 1825 (AM 366), f. 215v; 1828 (AM 376), f. 384v; 1829 (AM 377), ff. 208v, 321v y 396v; 1829 (AM 379), f. 152; 1839 (AM 396), f. 71v.

AHUS. Matrícula industrial. 1887-1891 (AM 1760), $1887-$ 1888 , ff. $22 r-22 v$ y $23 r ; 1888-1889$, f. 22 r y $23 r ; 1889-$ 1890 , f. 20 r y f. 21 r; $1890-1891$, f. $22 v$ y $23 v ; 1893-$ 1894 (AM 1761), ff. 19v-20r y 22v; 1896-1897 (AM 1764), ff. 22r, 23v y 24v; $1899-1900$ (AM 1767), ff. 24v, $25 \mathrm{v}, 26 \mathrm{v}$ y $27 \mathrm{v}$.

Boletín Oficial del Arzobispado de Santiago, 31 de diciembre de 1915, 11; Diario de Galicia, 7 de abril de 1918, 1; Galicia Diplomática, núm. 28-29, 22 de julio de 1888, 221.

\section{Bibliografía}

ALONSO BENITO, Javier. Platería. Colecciones del MNAD. Madrid: Ministerio de Educación, Cultura y Deporte, 2015.

ARRIBAS ÁLVAREZ, José Francisco. "El Registro Mercantil de Madrid: un acercamiento a la historia de empresas y empresarios (1830/1885 y 1914-1930)". Anuario del Instituto de Estudios Madrileños, 1990, 28, p. 629-642.

ARTIÑANO Y GALDÁCANO, Gervasio de (dir.). Orfebrería civil española (Celebrada en Madrid, 1925). Madrid: Sociedad Española de Amigos del Arte, 1925.

BAILLY-BAILLIÈRE, Charles. Anuario-almanaque del comercio, de la industria, de la magistratura y de la administración. Madrid: Carlos Bailly-Baillière, 18791911.

BAILLY-BAILLIÈRE, Charles; RIERA, Eduardo. Anuario General de España, Barcelona, Sociedad Anónima Anuarios Bailly -Baillière y Riera Reunidos, 1911-1924.

BARREIRO MALLÓN, Baudilio, "Los gremios compostelanos. Algunos datos y reflexiones". Estudios Compostelanos, 1976, 4, p. 181-200

BARRIOCANAL LÓPEZ, Yolanda. "Las Ordenanzas de los plateros compostelanos del año 1786". Minius, 19931994, 2-3, p. 149-156.

BARRIOCANAL LÓPEZ, Yolanda. El grabado compostelano del siglo XVIII. A Coruña: Fundación Pedro Barrié de la Maza, 1996

BELDA NAVARRO, Cristóbal; PEÑA VELASCO, María de la Concepción. "La visión de un mundo en crisis: los gremios frente a la Academia". En VALDÉS FERNÁNDEZ, M. (ed.). El arte español en épocas de transición. Actas del IX Congreso Nacional de Historia del Arte, vol. 2. León: Universidad de León, 1992, p. 17-25.

BOUZA BREY, Fermín. Platería civil compostelana hasta finales del siglo XIX. Santiago de Compostela: Instituto de Estudos Galegos Padre Sarmiento, 1962.

BOUZA BREY, Fermín. "La fecha de nacimiento y otros datos del orfebre compostelano Francisco Pecul". Compostellanum, 1964, IX-2, p. 139-140.

BRUQUETAS GALÁN, Rocío. "Los gremios, las ordenanzas, los obradores". En: GABALDÓN, A.; INEBA P. (dir.). La pintura europea sobre tabla siglos XV, XVI y XVII. Madrid: Ministerio de Cultura, 2010, p. 20-31.

CAMPOMANES, Pedro Rodríguez de; REEDER, John (ed.). Discurso sobre el fomento de la industria popular y Discurso sobre la educación popular de los artesanos y su fomento. Madrid: Instituto de Estudios Fiscales, 1975 [edición original: Madrid: Imprenta de Antonio de Sancha, 1774-1775].
CANEDO BARREIRO, María. "Oraciones en plata: estudio de la obra inédita de Jacobo Pecul Montenegro". Cuaderno de Estudios Gallegos, 2015, LXII-128, p. 141173.

CEBREIROS ÁLVAREZ, Eduardo. El municipio de Santiago de Compostela a finales del Antiguo Régimen (17591812). Santiago de Compostela: Escola Galega de Administración Pública, 1999.

COUSELO BOUZAS, José. Galicia artística en el siglo XVIII y primer tercio del XIX. Santiago de Compostela: Instituto de Estudos Galegos Padre Sarmiento, 2005 [edición original: Santiago de Compostela, Imp. y Enc. del Seminario Conciliar Central, 1933]

CRUZ VALDOVINOS José Manuel. Los plateros madrileños. Estudio histórico jurídico de su organización corporativa. Madrid: Gremio de Joyeros y Plateros de Madrid, 1983.

CRUZ VALDOVINOS, José Manuel. "Platería". En: BONET CORREA, A. (coord.). Historia de las Artes Aplicadas e Industriales en España. Madrid: Cátedra, 1987, p. 65158.

CRUZ VALDOVINOS, José Manuel. "Platería". En: BARTOLOMÉ, A. (dir.). Summa Artis, vol. XLV: Las artes decorativas en España II, vol. 2. Madrid: Espasa-Calpe, 1999, p. 511-610.

DALMASES BALAÑÁ, Nuria; GIRALT-MIRACLE, Daniel. Plateros y joyeros de Cataluña. Barcelona: Destino, 1985.

DEMERSON, Jorge; DEMERSON, Paula de. La Decadencia de las Reales Sociedades de Amigos del País. Oviedo: Universidad de Oviedo, 1977.

DÍEZ BENITO, Juan José. Las Escuelas Estatales de Artes y Oficios y la Educación del Obrero en España (18711900). Madrid: Villena Artes Gráficas S. A., 2002.

DÚO RÁMILA, Diana. Plateros portugueses en Galicia. El taller de los Cedeira (1542-1667). Tesis doctoral. Universidade de Santiago de Compostela, 2014.

ESCOLANO BENITO, Agustín. "Economía e llustración. EI origen de la Escuela técnica moderna en España". Historia de la Educación, 1982, 1, p. 169-191.

FERNÁNDEZ CASTIÑEIRAS, Enrique; FOLGAR DE LA CALLE, María del Carmen. "La Escuela de Dibujo de la Real Sociedad Económica de Amigos del País de Santiago de Compostela. Juan José Cancela del Río". En: ZALAMA, M. A.; MOGOLLÓN CANO-CORTÉS, P. (coords.). Alma Ars: estudios de arte e historia en homenaje al Dr. Salvador Andrés Ordax. Valladolid: Universidad de Valladolid, 2013, p. 321-328.

FERNÁNDEZ, Alejandro; MUNOA, Rafael; RABASCO, Jorge. Enciclopedia de la plata española y virreinal americana. Madrid: Torreángulo Arte Gráfico, 1984.

FERNÁNDEZ, Alejandro; MUNOA, Rafael; RABASCO, Jorge. Marcas de la plata española y virreinal. Madrid: Antiquaria, 1992.

GARCÍA CANTÚS, María Dolores. El gremio de plateros de Valencia en los siglos XVIII y XIX. Valencia: Ayuntamiento de Valencia, 1985.

GARCÍA CORTÉS, Carlos. Pedro Antonio Sánchez Vaamonde (1749-1806): un promotor de la Ilustración en Galicia. A Coruña: Biblioteca de la Casa del Consulado, 2003.

HERNÁNDEZ FRANCO, Juan. La gestión política y el pensamiento reformista del Conde de Floridablanca. Murcia: Universidad de Murcia, 2008.

HERRERO MARTíN, María Jesús. La orfebrería en las parroquias compostelanas. Tesis de licenciatura. Universidade de Santiago de Compostela, 1987. 
HERRERO PASCUAL, Ana María; MONTOJO MONTOJO, Vicente. "El registro mercantil, fuente para la historia económica: la documentación del Archivo Histórico Provincial de Murcia". Tabula: revista de archivos de Castilla y León, 2002, 5, p. 233-244.

KAWAMURA KAWAMURA, Yayoi; SÁEZ GONZÁLEZ, Manuela. Arte de la platería en la Mariña lucense, siglos XVI, XVII, XVIII. Lugo: Diputación Provincial de Lugo, 1999.

LARRIBA LEIRA, Mariel. "La orfebrería". En: GARCÍA IGLESIAS, X. M. (dir.). San Martiño Pinario. Inventario. Santiago de Compostela: Xunta de Galicia, 2000, p. 83-97.

LÓPEZ VÁZQUEZ, José Manuel. "Do Neoclasicismo a 1950". En: LÓPEZ VÁZQUEZ, J. M.; SEARA MORALES, I., Galicia Arte, Tomo XV: Arte Contemporánea (I). A Coruña: Hércules, 1993, p. 136-319.

LOUZAO MARTínEZ, Xosé Manuel. Catálogo del Museo de Arte Sacro de La Coruña. Barcelona: Dúplex, 1993.

MARTín, Fernando (com.). El aragonés Antonio Martínez y su fábrica de platería en Madrid (celebrada en Madrid, 2011). Madrid: Museo de Historia, 2011.

MARTíN ACEÑA, Pablo. La creación de sociedades en Madrid (1830-1848): Un análisis del primer registro mercantil. Madrid: Fundación Empresa Pública, 1993.

MOLIST FRADE, Beatriz. La orfebrería religiosa de los siglos XVII-XIX en la ciudad de La Coruña: Catalogación. Tesis de licenciatura. Universidade de Santiago de Compostela, 1986.

MONTOJO MONTOJO, Vicente. "Las sociedades mercantiles a través del registro mercantil de Murcia en la época de la Restauración (1886-1909)". Mvrgetana, 2002, LXII-124, p. 133-158.

PÉREZ COSTANTI, Pablo. Notas viejas galicianas, A Coruña, Xunta de Galicia, 1933 [edición original: Vigo, Imprenta de los Sindicatos Católicos, 1925-1927].

PÉREZ RODRÍGUEZ, Fernando. El arquitecto Miguel Ferro Caaveyro (1740-1807). Tesis doctoral. Universidade de Santiago de Compostela, 2010.

PÉREZ VARELA, Ana. "Obras de platería de José Losada para la catedral de Santiago de Compostela: Fuentes para su estudio y análisis de las piezas". En: RIVAS CARMONA, J. (coord.), Estudios de platería San Eloy. Murcia: Universidad de Murcia, 2016, p. 505-522.

PÉREZ VARELA, Ana. "Hacia una reconstrucción de la historia del gremio de San Eloy de Santiago de Compos- tela: el siglo XVI". En: RIVAS CARMONA, J. (coord.). Estudios de platería San Eloy. Murcia: Universidad de Murcia, 2017, p. 495-509.

PÉREZ VARELA, Ana. "El gremio de San Eloy de Santiago de Compostela en el siglo XVIII". En: RIVAS CARMONA, J.; GARCÍA ZAPATA, I. J. (coord.), Estudios de platería San Eloy. Murcia: Universidad de Murcia, 2018, p. 403-416.

PÉREZ VARELA, Ana. Vida y obra del platero compostelano Ricardo Martínez Costoya: vida, obra y catálogo (1859-1927). Tesis doctoral. Universidade de Santiago de Compostela, 2019.

POLT, John. Gaspar Melchor de Jovellanos. Nueva York: Twayne, 1971.

POSE ANTELO, José Manuel. La ciudad de Santiago en la primera etapa de la Restauración: 1875-1902: sociedad, economía y cultura. Tesis doctoral. Universidade de Santiago de Compostela, 1989.

POSE ANTELO, José Manuel. La economía y la sociedad compostelanas a finales del siglo XIX. Santiago de Compostela: Universidade de Santiago de Compostela. 1992.

REMUÑ́́N FERRO, Manuel. "Gremios compostelanos relacionados con la peregrinación jacobea". En: SCALIA, G. (coord.). Atti del Convegno Internazionale di Studi il Pellegrinaggio a Santiago de Compostela e la Letteratura Jacopea. Perugia: Centro Italiano Studi Compostellani, 1983, p. 109-126.

RIERA, Eduardo. Guía práctica de industria y comercio de España, Barcelona, Centro de propaganda mercantil, p. 1901-1911.

RODRÍGUEZ GONZÁLEZ, Ángel. "Cofradías y gremios de Santiago". Compostellanum, 1986, 31, 3-4, p. 463-473.

RODRÍGUEZ GONZÁLEZ, Ángel. "Notas para la historia de Compostela (1879-1975)". En: BERNAL, D. (et. al.). Compostela na Historia: redescubrimiento-rexurdimento. Santiago de Compostela: Xunta de Galicia, 1999, p. 25-36.

SÁNCHEZ-LAFUENTE GÉMAR, Rafael. El arte de la platería en Málaga, 1550/1800. Málaga: Universidad de Málaga, 1997.

SOUSA, José; PEREIRA, Fernando. Historia de la Escuela de Artes y Oficios de Santiago. A Coruña: Editorial Diputación Provincial, 1988. 
